\title{
All Pass Network Based MSO Using OTRA
}

\author{
Rajeshwari Pandey, ${ }^{1}$ Neeta Pandey, ${ }^{1}$ Romita Mullick, ${ }^{1}$ \\ Sarjana Yadav, ${ }^{1}$ and Rashika Anurag ${ }^{2}$ \\ ${ }^{1}$ Department of Electronics and Communication Engineering, Delhi Technological University, Delhi 110042, India \\ ${ }^{2}$ Department of Electronics and Communication Engineering, JSS Academy of Technical Education, C-20/1, \\ Sector 62, Noida, Uttar Pradesh 201301, India
}

Correspondence should be addressed to Neeta Pandey; n66pandey@rediffmail.com

Received 24 August 2014; Accepted 1 December 2014

Academic Editor: Liwen Sang

\begin{abstract}
Copyright (c) 2015 Rajeshwari Pandey et al. This is an open access article distributed under the Creative Commons Attribution License, which permits unrestricted use, distribution, and reproduction in any medium, provided the original work is properly cited.

This paper presents multiphase sinusoidal oscillators (MSOs) using operational transresistance amplifier (OTRA) based all pass networks. Both even and odd phase oscillations of equal amplitudes which are equally spaced in phase can be produced using single all pass section per phase. The proposed MSOs provide voltage output and can readily be used for driving voltage input circuits without increasing component count. The effect of nonideality of OTRA on the circuit performance is also analysed. The functionality of the proposed circuit is verified through PSPICE simulations.
\end{abstract}

\section{Introduction}

Multiphase sinusoidal oscillators (MSO) provide multiple outputs of the same frequency, equally spaced in phase, and find extensive application in the field of communications, instrumentation, and power electronics. In communications MSO circuits are used in single-sideband generators, phase modulators, and quadrature mixers [1]. Selective voltmeters and vector generator are common applications of MSOs in the field of instrumentation [2]. In power electronics threephase MSOs are frequently utilized in PWM converters [3] and inverters [4].

A large number of MSO realizations using various analog building blocks (ABB) [2,5-25] are available in literature. These MSOs are based on a basic design philosophy of forming closed loop using $n(n \geq 3)$ cascaded phase shifting networks thereby producing $n$ equally spaced phases. For phase shifting either first-order low pass networks (LPNs) $[5-7,9-21,24,25]$ or first-order all pass networks (APNs) $[2,8,22,23]$ are used. These reported structures provide either voltage [5-16] or current $[2,17-24]$ outputs.

The MSOs of [5-8] are realized using operational amplifiers (op-amps). However due to constant gain-bandwidth product and lower slew rate of the op-amps, their high frequency operations are limited. Additionally the active $R$ implementations of $[5,6]$ lack tunability as these structures make use of the op-amp parasitic capacitance. The current feedback operational amplifier (CFOA) based MSO structure [9] is capable of producing high frequencies but requires an accessible compensation terminal of a CFOA. The MSOs of $[10,11]$ are OTA based electronically tunable structures; however, they provide voltage output at high impedance making a buffer necessary to drive the voltage input circuits. In addition, for both the structures the output voltage is temperature sensitive too. The MSO configurations presented in [12-15] are CC based designs and provide voltage output at high impedance. Further the MSO of [14], being active $R$ structure, lacks tunability. Three topologies of OTRA based MSOs are proposed in [16] and are designed using LPNs. The structures proposed in [2,17-25] provide current outputs which need to be converted back to voltage for circuits requiring voltage inputs, which would considerably increase the component count. A detailed comparison of these structures is given in Table 1 which suggests that OTRA based MSO is the most suitable choice for voltage output.

In this paper authors aim at presenting OTRA based MSO, designed using APNs. The proposed circuit utilizes $n(n \geq 3)$ APNs to produce $n$ phase oscillations of equal 
TABLE 1: Detailed comparison of available MSOs.

\begin{tabular}{|c|c|c|c|c|c|}
\hline Reference & $\mathrm{ABB}$ & Phase shift network & Output & Output impedance & Tunability \\
\hline$[2]$ & CCCDTA & APN & Current & High & Yes \\
\hline$[5]$ & Op-amp & LPN & Voltage & Low & No \\
\hline$[6]$ & Op-amp & LPN & Voltage & Low & No \\
\hline$[7]$ & Op-amp & LPN & Voltage & Low & Yes \\
\hline$[8]$ & Op-amp & APN & Voltage & Yes & Yes \\
\hline$[9]$ & CFOA & LPN & Voltage & No & Yes \\
\hline$[10]$ & OTA & LPN & Voltage & High & Yes \\
\hline$[11]$ & OTA & LPN & Voltage & High & Yes \\
\hline$[12]$ & CCII & LPN & Voltage & High & Yes \\
\hline$[13]$ & CCII & LPN & Voltage & High & Yes \\
\hline$[14]$ & CCII & LPN & Voltage & High & No \\
\hline$[15]$ & CCII & LPN & Voltage & High & Yes \\
\hline$[16]$ & OTRA & LPN & Voltage & Low & Yes \\
\hline$[17]$ & Current follower & LPN & Current & High & Yes \\
\hline$[18]$ & CCII & LPN & Current & High & Yes \\
\hline$[19]$ & CCII & LPN & Current & High & Yes \\
\hline$[20]$ & CCII & LPN & Current & High & Yes \\
\hline$[21]$ & CDTA & LPN & Current & High & Yes \\
\hline$[22]$ & CDTA & APN & Current & High & Yes \\
\hline [23] & CDTA & APN & Current & High & Yes \\
\hline$[24]$ & $\mathrm{CC}$ & LPN & Current & High & Yes \\
\hline$[25]$ & CFTA & LPN & Current & High & Yes \\
\hline Proposed work & OTRA & APN & Voltage & Low & Yes \\
\hline
\end{tabular}

amplitudes with a phase difference of $(360 / n)^{\circ}$. The APN can produce a phase shift up to $180^{\circ}$ as against a maximum of $90^{\circ}$ produced by LPN. As a result the APN based scheme can be used to implement an even phase system for $n=4$ also whereas $n=6$ is the minimum for the systems designed using LPNs [8].

\section{Circuit Description}

In this section the generalized APN based MSO scheme [8] is described first which is followed by the design adaption using OTRA.

2.1. The APN Based MSO Design Scheme. The APN based MSO structure consists of $n$ cascaded first-order APN blocks. The output of the $n$th stage is fed back to the input of the first stage thus forming a closed loop as shown in Figure 1(a). The output of $n$th stage is fed back directly for odd phase system whereas for even phase system it is inverted, for sustained oscillations. In case of even phased system the structure can be modified for obtaining $n$ even phased oscillations by replacing $n / 2$ APN with $n / 2$ inverters as shown in Figure 1(b).

The transfer function $G(s)$ of each APN block is given by

$$
G(s)=K \frac{(1-s \tau)}{(1+s \tau)},
$$

where $K$ represents the gain and time constant $\tau$ determines the corner frequency of the APN. The phase $(\phi)$ of each APN block is computed to be

$$
\phi=-2 \tan ^{-1}(\omega \tau) .
$$

Thus an APN can introduce signal phase lag from 0 to $180^{\circ}$ as frequency $\omega$ varies from zero to infinity. From Figure 1 the open loop gain $L(s)$ can be expressed as

$$
L(s)=K^{n}\left(\frac{(1-s \tau)}{(1+s \tau)}\right)^{n} .
$$

The Barkhausen criterion [26] for sustained oscillations at a frequency $\omega_{0}$ can be expressed by

$$
\begin{gathered}
\left|L\left(j \omega_{0}\right)\right|=K^{n}\left(\frac{1-j \omega_{0} \tau}{1+j \omega_{0} \tau}\right)^{n}=1, \\
\angle\left|L\left(j \omega_{0}\right)\right|=n \phi=-2 \pi .
\end{gathered}
$$

Since $\left(\left(1-j \omega_{0} \tau\right) /\left(1+j \omega_{0} \tau\right)\right)^{n}=1$, (4) results in condition of oscillation (CO) as

$$
\mathrm{CO}: K=1 \text {. }
$$

Substituting from (2) in (5) total phase shift of the loop can be computed as

$$
n\left(-2 \tan ^{-1}\left(\omega_{0} \tau\right)\right)=-2 \pi
$$




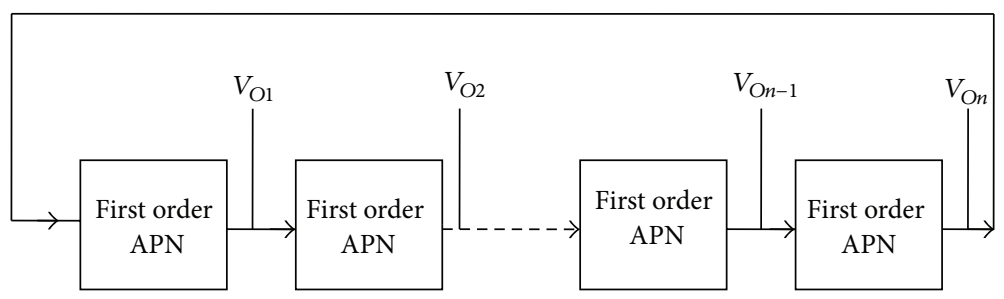

(a)

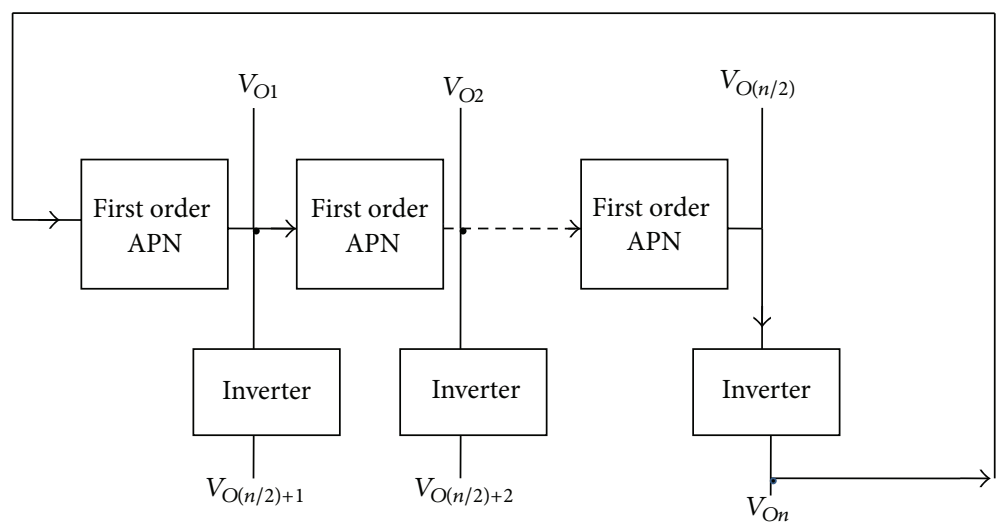

(b)

FIGURE 1: Generalized APN based MSO structure for producing $n$ phase oscillations. (a) Odd phased oscillations. (b) Even phased oscillations.

Equation (7) will converge only for values of $n$ such that $n \geq 3$. This results in frequency of oscillation (FO) as

$$
\text { FO }: f_{0}=\frac{1}{2 \pi \tau} \tan \left(\frac{\pi}{n}\right)
$$

The spacing between different phases is given by

$$
\phi=\frac{2 \pi}{n} \text {. }
$$

Thus the circuit gives rise to equally spaced oscillations having a phase difference of $(360 / n)^{\circ}$.

2.2. The OTRA Based MSO Implementation. The OTRA is a high gain, current input voltage output $\mathrm{ABB}$. The circuit symbol of OTRA is shown in Figure 2 and the port characteristics in matrix form are given by (10), where $R_{m}$ is transresistance gain of OTRA. For ideal operations the $R_{m}$ of OTRA approaches infinity and forces the input currents to be equal. Thus OTRA must be used in a negative feedback configuration $[25,27]$ :

$$
\left[\begin{array}{c}
V_{p} \\
V_{n} \\
V_{O}
\end{array}\right]=\left[\begin{array}{rrr}
0 & 0 & 0 \\
0 & 0 & 0 \\
R_{m} & -R_{m} & 0
\end{array}\right]\left[\begin{array}{l}
I_{p} \\
I_{n} \\
I_{O}
\end{array}\right] .
$$

The MSO scheme outlined in Section 2.1 can be implemented using OTRA based first-order all pass sections. The OTRA based APN proposed in [27] and shown in Figure 3 is used for MSO implementation.

The transfer function of the APN can be written as

$$
G(s)=\frac{V_{O}(s)}{V_{i}(s)}=K \frac{(1-s \tau)}{(1+s \tau)},
$$

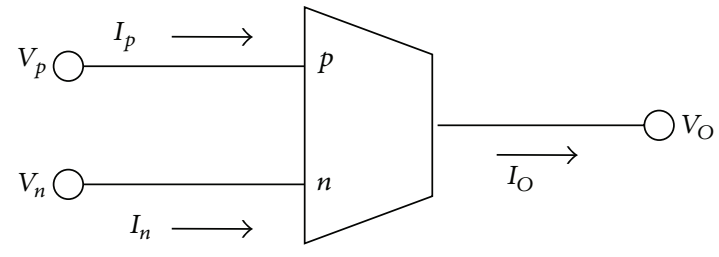

FIgURE 2: OTRA circuit symbol.

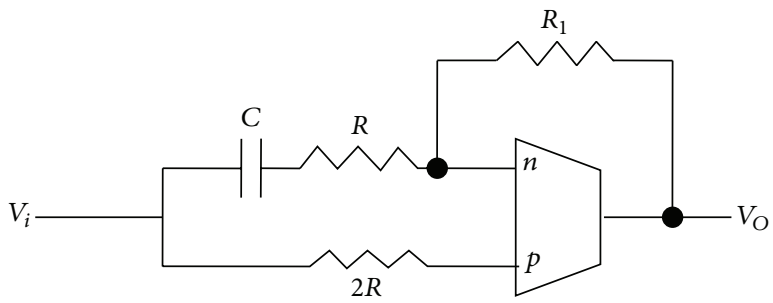

Figure 3: The OTRA based APN [27].

where

$$
K=\frac{R_{1}}{2 R}, \quad \tau=\frac{1}{C R},
$$

and the phase relation is expressed as

$$
\phi=-2 \tan ^{-1}(\omega C R) .
$$




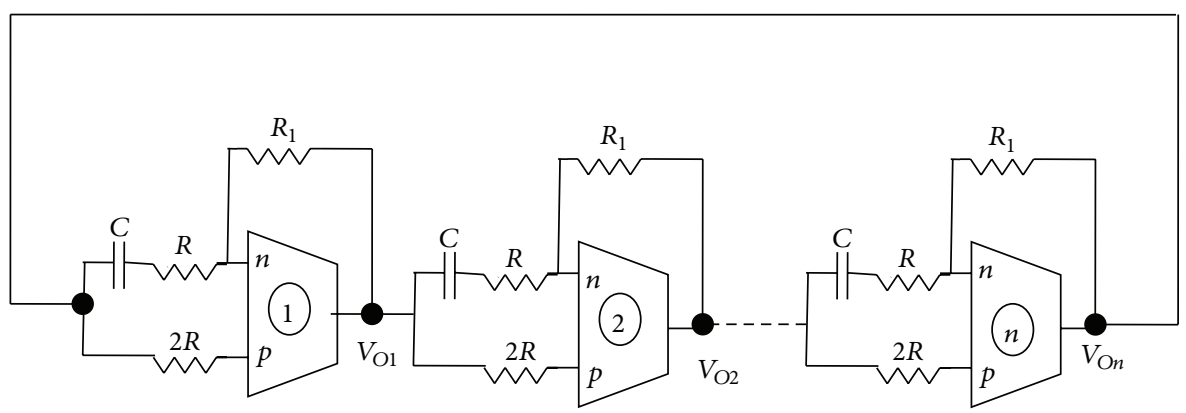

(a)

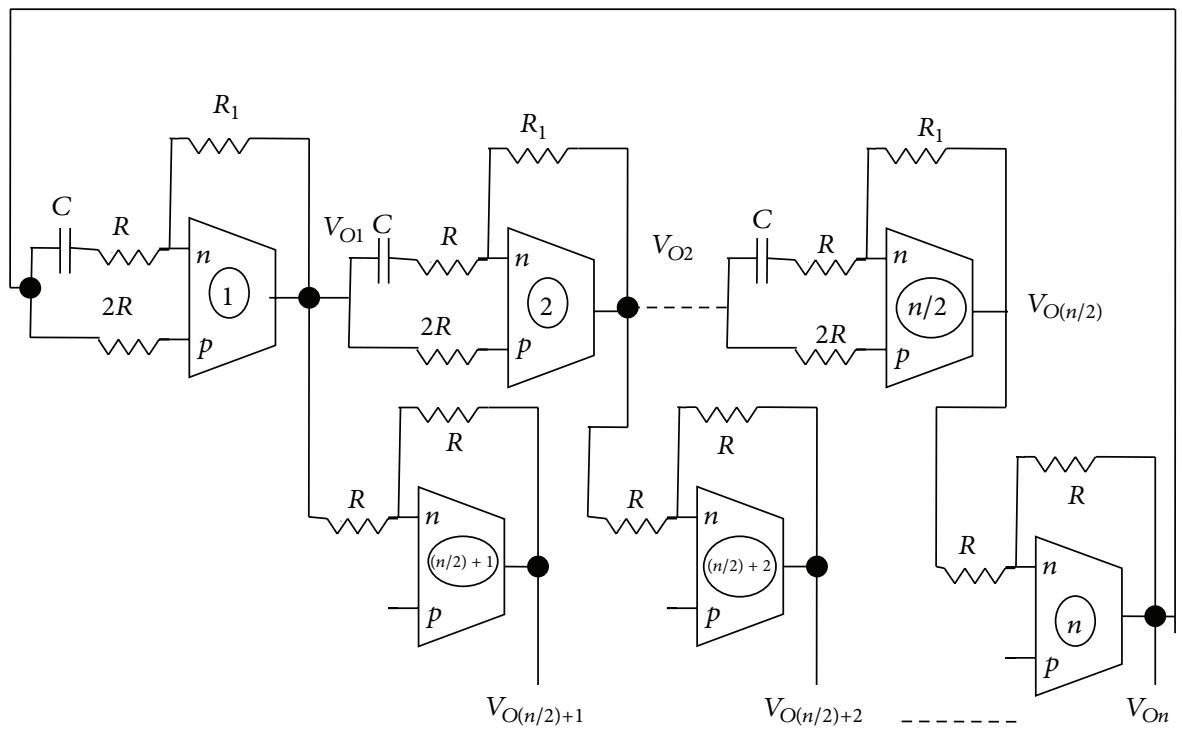

(b)

FIGURE 4: The OTRA based MSO circuits: (a) odd phased, (b) even phased.

The OTRA based odd and even phased MSO structures are shown in Figures 4(a) and 4(b), respectively. The loop gain can be written as

$$
L(s)=\left(\frac{R_{1}}{2 R}\right)^{n}\left(\frac{(1-s / R C)}{(1+s / R C)}\right)^{n} .
$$

$\mathrm{CO}$ and $\mathrm{FO}$ can be expressed as

$$
\begin{aligned}
& \mathrm{CO}: R_{1}=2 R, \\
& \mathrm{FO}: f_{0}=\frac{1}{2 \pi R C} \tan \left(\frac{\pi}{n}\right) .
\end{aligned}
$$

\section{Nonideality Analysis}

Ideally the transresistance gain $R_{m}$ is assumed to approach infinity. However, practically $R_{m}$ is a frequency dependent finite value. Considering a single pole model for the transresistance gain, $R_{m}$ can be expressed as

$$
R_{m}(s)=\left(\frac{R_{0}}{1+s / \omega_{0}}\right)
$$

For high frequency applications the transresistance gain $R_{m}(s)$ reduces to

$$
R_{m}(s)=\left(\frac{1}{s C_{p}}\right) \quad \text { where } C_{p}=\left(\frac{1}{R_{0} \omega_{0}}\right) .
$$

$C_{p}$ is known as parasitic capacitance of OTRA. Taking the effect of $C_{p}$ into account (11) modifies to

$$
G(s)=\frac{R_{1}}{2 R}\left(\frac{(1-s C R)}{(1+s C R)\left(1+s C_{p} R_{1}\right)}\right) .
$$

Thus the $C_{p}$ of OTRA results in introduction of another pole having pole frequency $\omega_{p}=1 / R_{1} C_{p}$. However with the value of $C_{p}$ being small (typically $5 \mathrm{pF}$ ) the parasitic pole frequency would be far off from the operating frequency of the APN and would not affect the MSO operation.

\section{Simulation Results}

The proposed circuits are simulated using PSPICE to validate the theoretical predictions. The CMOS realization of OTRA presented in [28] and reproduced in Figure 5 is used for 


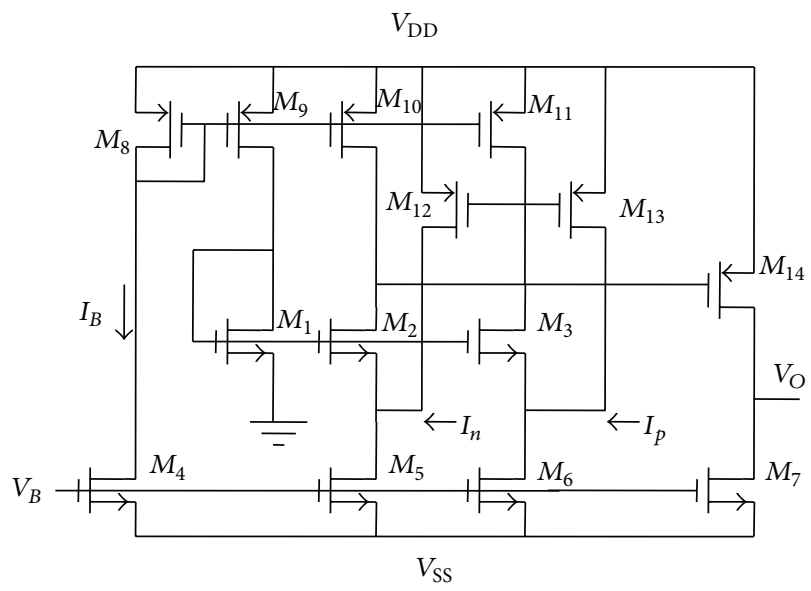

Figure 5: The CMOS implementation of OTRA [28].

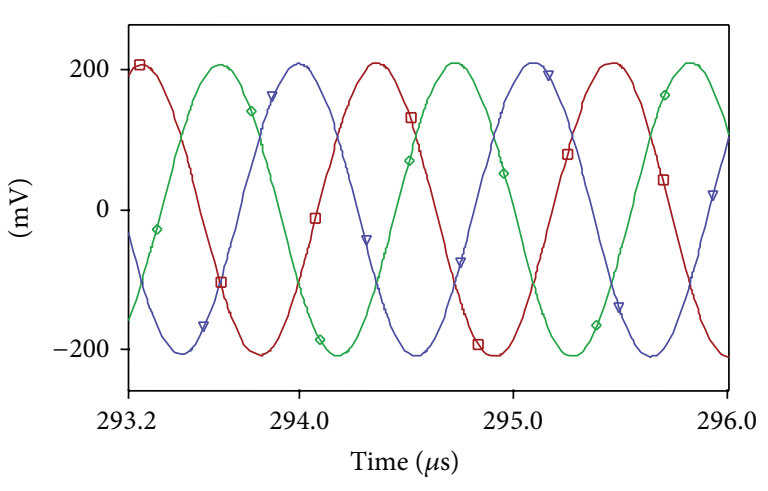

(a)

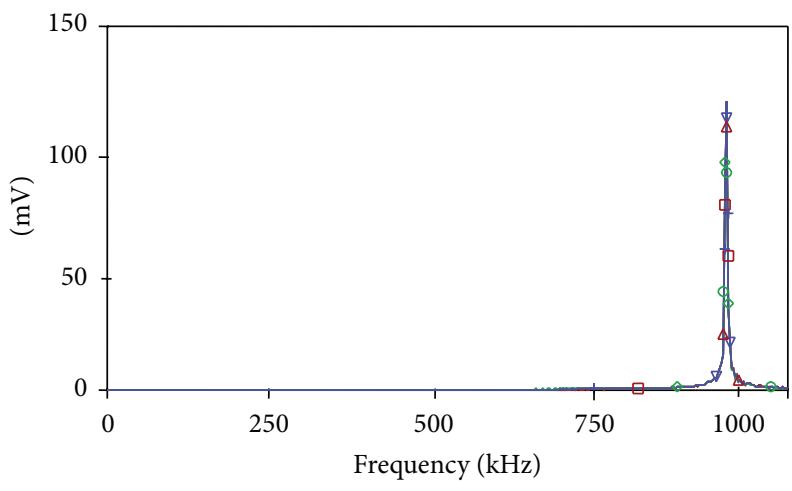

(b)

Figure 6: Odd phased MSO output for $n=3$ : (a) steady state output; (b) frequency spectrum.

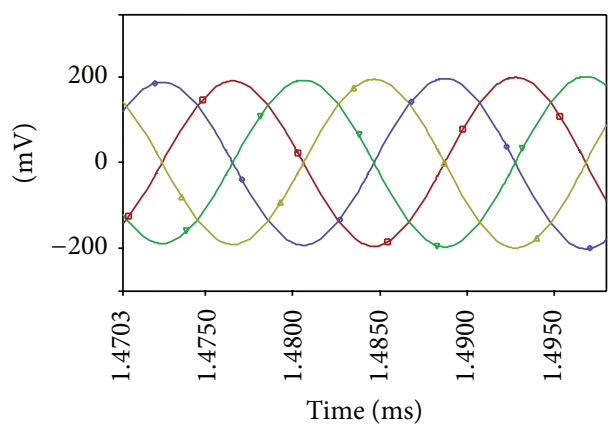

(a)

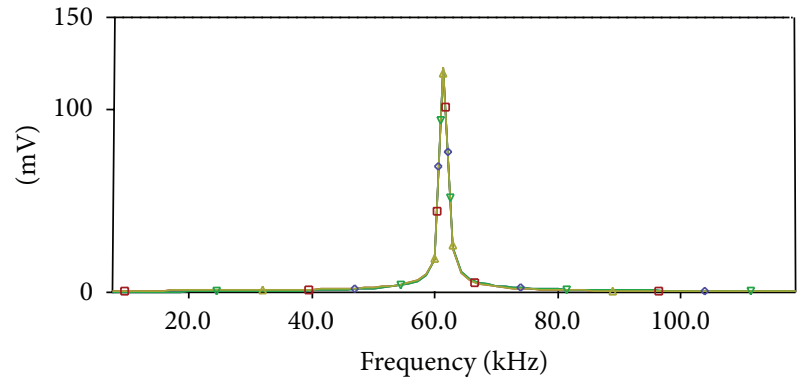

(b)

FIGURE 7: Even phased MSO output for $n=4$ : (a) steady state output; (b) frequency spectrum.

simulation. The output of the MSO of Figure 4(a) for $n=$ 3 , with component values $R=2.5 \mathrm{~K} \Omega, R_{1}=5 \mathrm{~K} \Omega$, and $C=0.1 \mathrm{nF}$, is depicted in Figure 6. The steady state output is shown in Figure 6(a) while the frequency spectrum is depicted in Figure 6(b). The simulated frequency of oscillations is observed to be $1 \mathrm{MHz}$ against the calculated value of $1.1 \mathrm{MHz}$.
Simulation results for $n=4$, with component values $R=$ $2.5 \mathrm{~K} \Omega, R_{1}=5 \mathrm{~K} \Omega$, and $C=1 \mathrm{nF}$, are depicted in Figure 7 . The simulated frequency is found to be $61.69 \mathrm{KHz}$ while the theoretical calculation yields an $\mathrm{FO}$ of $63.69 \mathrm{KHz}$.

It may be observed from (8) that the FO can be varied either through $R$ or by changing $C$. Variation of FO with respect to $R$ while keeping $C=1 \mathrm{nF}$ has been depicted in 


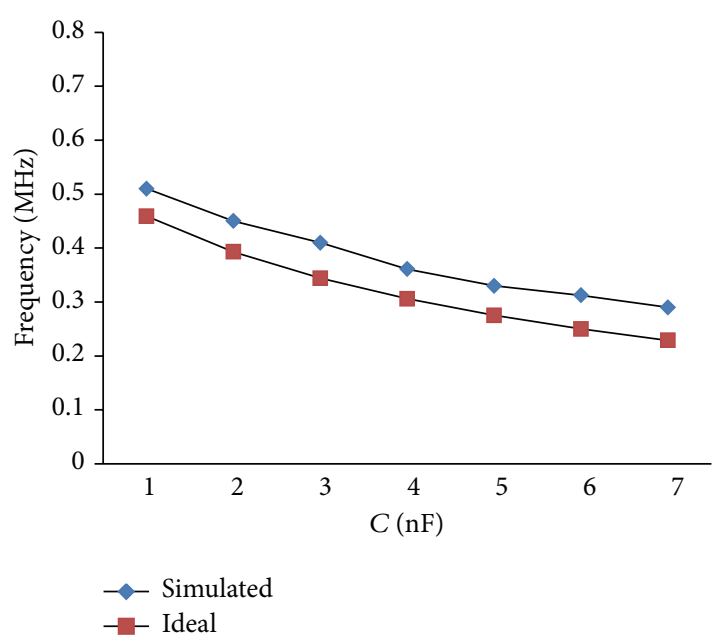

(a)

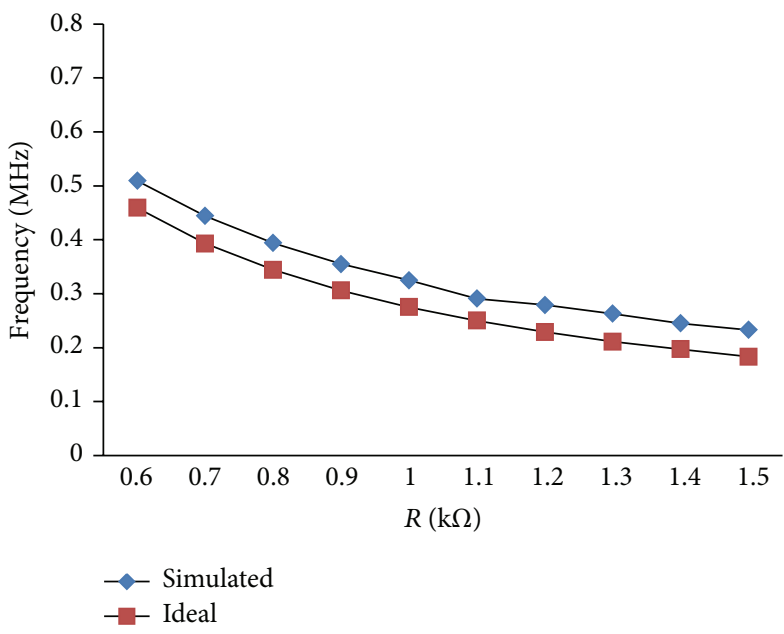

(b)

FIgURE 8: Frequency tuning of MSO (a) with $R$ and (b) with $C$.

Figure 8(a) whereas tuning with $C$ is shown in Figure 8(b) with $R=0.5 \mathrm{~K} \Omega$. It shows that the simulated values closely follow the theoretically calculated values.

\section{Conclusion}

In this work OTRA based MSO circuits, designed using first-order all pass networks, are presented. The proposed structures produce " $n$ " phase oscillations of equal amplitudes which are equally spaced in phase. These circuits provide voltage output at low impedance and thus can readily be used to drive voltage input circuits without increasing component count. The proposed circuits are very accurate in providing the desired phase shift. The workability of the circuit has been demonstrated through PSPICE simulations.

\section{Conflict of Interests}

The authors declare that there is no conflict of interests regarding the publication of this paper.

\section{References}

[1] W. Tomasi, Electronic Communications System, Prentice-Hall, Upper Saddle River, NJ, USA, 1998.

[2] W. Jaikla and P. Prommee, "Electronically tunable currentmode multiphase sinusoidal oscillator employing CCDTAbased allpass filters with only grounded passive elements," Radioengineering, vol. 20, no. 3, pp. 594-599, 2011.

[3] D. C. Lee and Y. S. Kim, "Control of single-phase-to-three-phase $\mathrm{AC} / \mathrm{DC} / \mathrm{AC}$ PWM converters for induction motor drives," IEEE Transactions on Industrial Electronics, vol. 54, no. 2, pp. 797-804, 2007.

[4] V. P. Ramamurthi and B. Ramaswami, "A novel three-phase reference sine wave generator for PWM invertors," IEEE Transactions on Industrial Electronics, vol. 1, no. 3, pp. 235-240, 1982.
[5] M. T. Abuelma'atti and W. A. Almansoury, "Active-R multiphase oscillators," IEE Proceedings G: Electronic Circuits and Systems, vol. 134, no. 6, pp. 292-294, 1987.

[6] D. Stiurca, "On the multiphase symmetrical active-R oscillators," IEEE Transactions on Circuits and Systems II, vol. 41, no. 2, pp. 156-158, 1994.

[7] S. J. G. Gift, "Multiphase sinusoidal oscillator using invertingmode operational amplifiers," IEEE Transactions on Instrumentation and Measurement, vol. 47, no. 4, pp. 986-991, 1998.

[8] S. J. G. Gift, "The application of all-pass filters in the design of multiphase sinusoidal systems," Microelectronics Journal, vol. 31, no. 1, pp. 9-13, 2000.

[9] D.-S. Wu, S.-I. Liu, Y.-S. Hwang, and Y.-P. Wu, "Multiphase sinusoidal oscillator using the CFOA pole," IEE Proceedings: Circuits, Devices and Systems, vol. 142, no. 1, pp. 37-40, 1995.

[10] C.-L. Hou, J.-S. Wu, J. Hwang, and H.-C. Lin, "OTA-based evenphase sinusoidal oscillators," Microelectronics Journal, vol. 28, no. 1, pp. 49-54, 1997.

[11] I. A. Khan, M. T. Ahmed, and N. Minhaj, “Tunable OTAbased multiphase sinusoidal oscillators," International Journal of Electronics, vol. 72, no. 3, pp. 443-450, 1992.

[12] D.-S. Wu, S.-I. Liu, Y.-S. Hwang, and Y.-P. Wu, "Multiphase sinusoidal oscillator using second-generation current conveyors," International Journal of Electronics, vol. 78, no. 4, pp. 645651, 1995.

[13] C.-L. Hou and B. Shen, "Second-generation current conveyorbased multiphase sinusoidal oscillators," International Journal of Electronics, vol. 78, no. 2, pp. 317-325, 1995.

[14] M. T. Abuelma'atti and M. A. Al-Qahtani, "A grounded-resistor current conveyor-based active- $\mathrm{R}$ multiphase sinusoidal oscillator," Analog Integrated Circuits and Signal Processing, vol. 16, no. 1, pp. 29-34, 1998.

[15] G. D. Skotis and C. Psychalinos, "Multiphase sinusoidal oscillators using second generation current conveyors," $A E U-$ International Journal of Electronics and Communications, vol. 64, no. 12, pp. 1178-1181, 2010. 
[16] R. Pandey, N. Pandey, M. Bothra, and S. K. Paul, "Operational transresistance amplifier-based multiphase sinusoidal oscillators," Journal of Electrical and Computer Engineering, vol. 2011, Article ID 586853, 8 pages, 2011.

[17] M. T. Abuelma'atti, "Current-mode multiphase oscillator using current followers," Microelectronics Journal, vol. 25, no. 6, pp. 457-461, 1994.

[18] M. T. Abuelma'Atti and M. A. Al-Qahtani, "A new currentcontrolled multiphase sinusoidal oscillator using translinear current conveyors," IEEE Transactions on Circuits and Systems II: Analog and Digital Signal Processing, vol. 45, no. 7, pp. 881885, 1998.

[19] M. T. Abuelma'atti and M. A. Al-Qahtani, "Low component second-generation current conveyor-based multiphase sinusoidal oscillator," International Journal of Electronics, vol. 84, no. 1, pp. 45-52, 1998.

[20] C. Loescharataramdee, W. Kiranon, W. Sangpisit, and W. Yadum, "Multiphase sinusoidal oscillators using translinear current conveyors and only grounded passive components," in Proceedings of the 33rd Southeastern Symposium on System Theory, pp. 59-63, IEEE, Athens, Ga, USA, March 2001.

[21] W. Tangsrirat and W. Tanjaroen, "Current-mode multiphase sinusoidal oscillator using current differencing transconductance amplifiers," Circuits, Systems, and Signal Processing, vol. 27, no. 1, pp. 81-93, 2008.

[22] W. Tangsrirat, W. Tanjaroen, and T. Pukkalanun, "Currentmode multiphase sinusoidal oscillator using CDTA-based allpass sections," AEU-International Journal of Electronics and Communications, vol. 63, no. 7, pp. 616-622, 2009.

[23] W. Jaikla, M. Siripruchyanun, D. Biolek, and V. Biolkova, "Highoutput-impedance current-mode multiphase sinusoidal oscillator employing current differencing transconductance amplifierbased allpass filters," International Journal of Electronics, vol. 97, no. 7, pp. 811-826, 2010.

[24] M. Kumngern, J. Chanwutitum, and K. Dejhan, "Electronically tunable multiphase sinusoidal oscillator using translinear current conveyors," Analog Integrated Circuits and Signal Processing, vol. 65, no. 2, pp. 327-334, 2010.

[25] P. Uttaphut, "Realization of electronically tunable current mode multiphase sinusoidal oscillators using CFTAs," World Academy of Science, Engineering and Technology, vol. 6, pp. 657-660, 2012.

[26] A. S. Sedra and K. C. Smith, Microelectronic Circuits, Oxford University Press, New York, NY, USA, 2004.

[27] S. Kilinç and U. Çam, "Cascadable allpass and notch filters employing single operational transresistance amplifier," Computers and Electrical Engineering, vol. 31, no. 6, pp. 391-401, 2005.

[28] H. Mostafa and A. M. Soliman, "A modified realization of the OTRA," Frequenz, vol. 60, no. 3-4, pp. 70-76, 2006. 

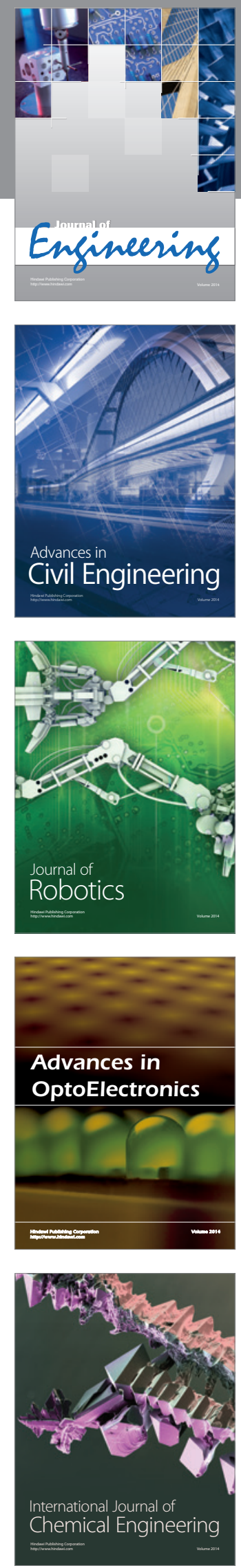

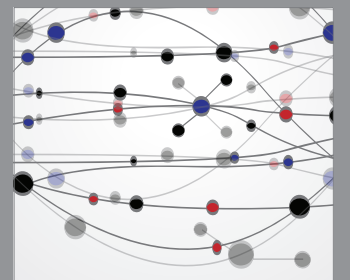

The Scientific World Journal
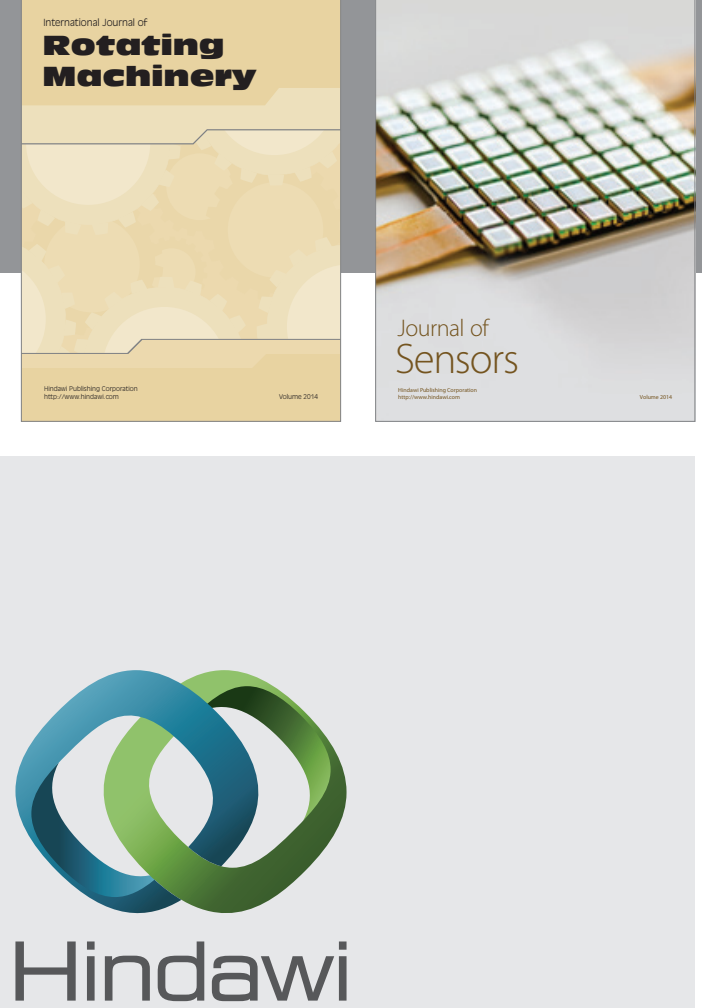

Submit your manuscripts at http://www.hindawi.com
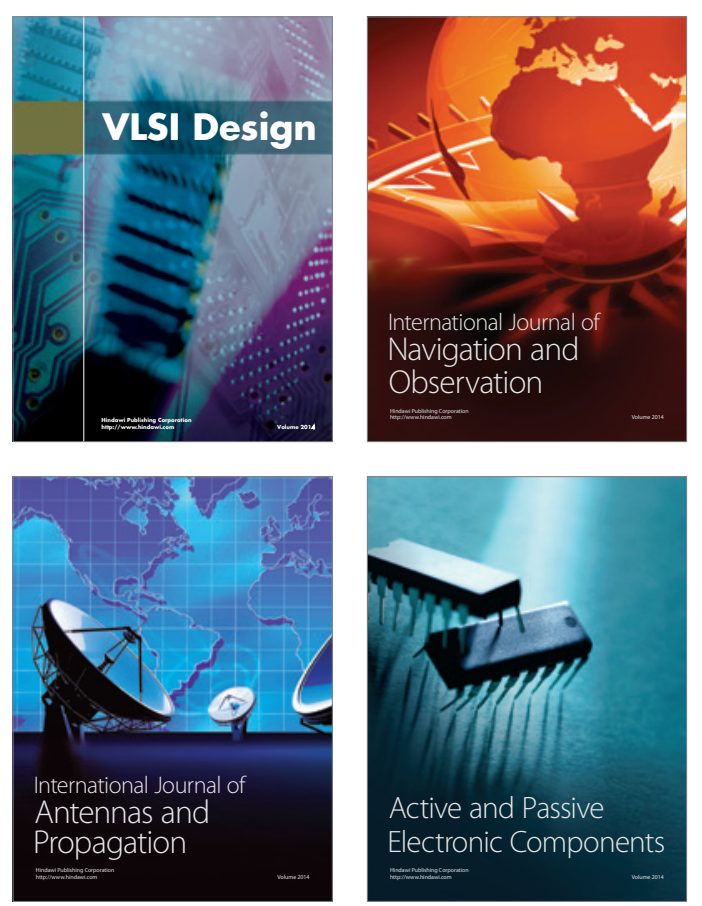
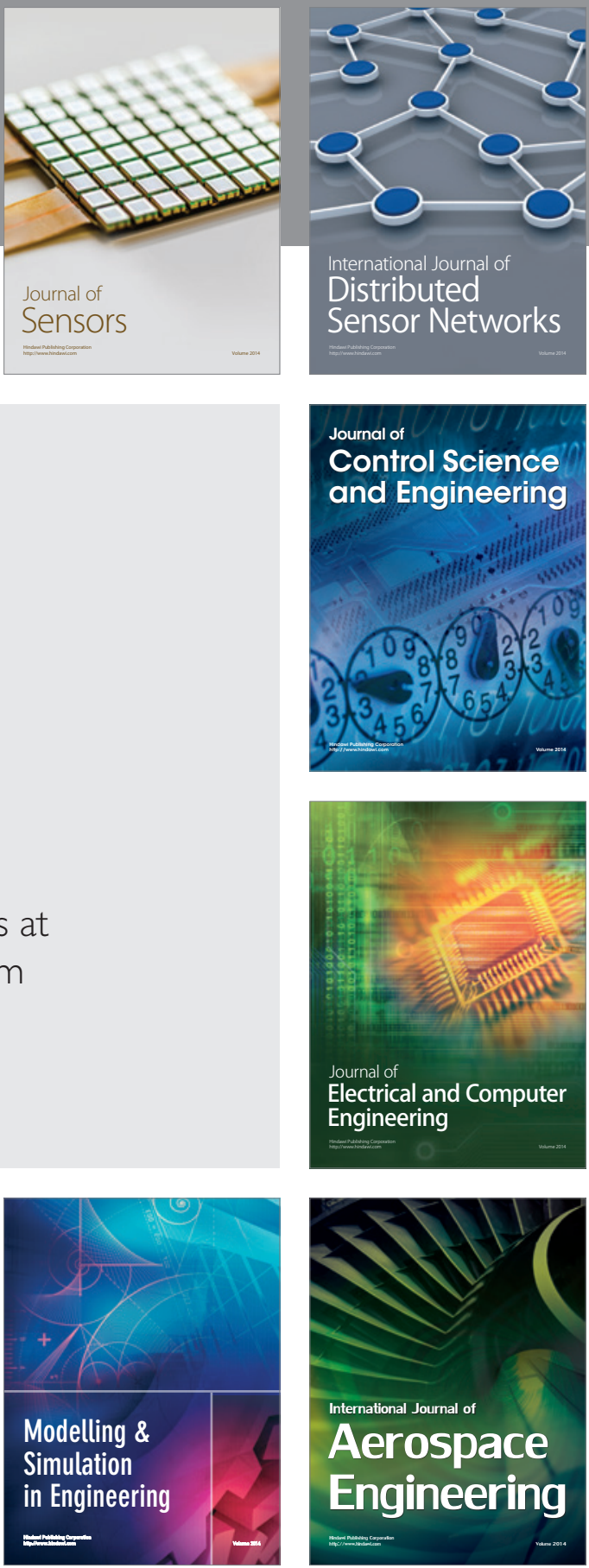

Journal of

Control Science

and Engineering
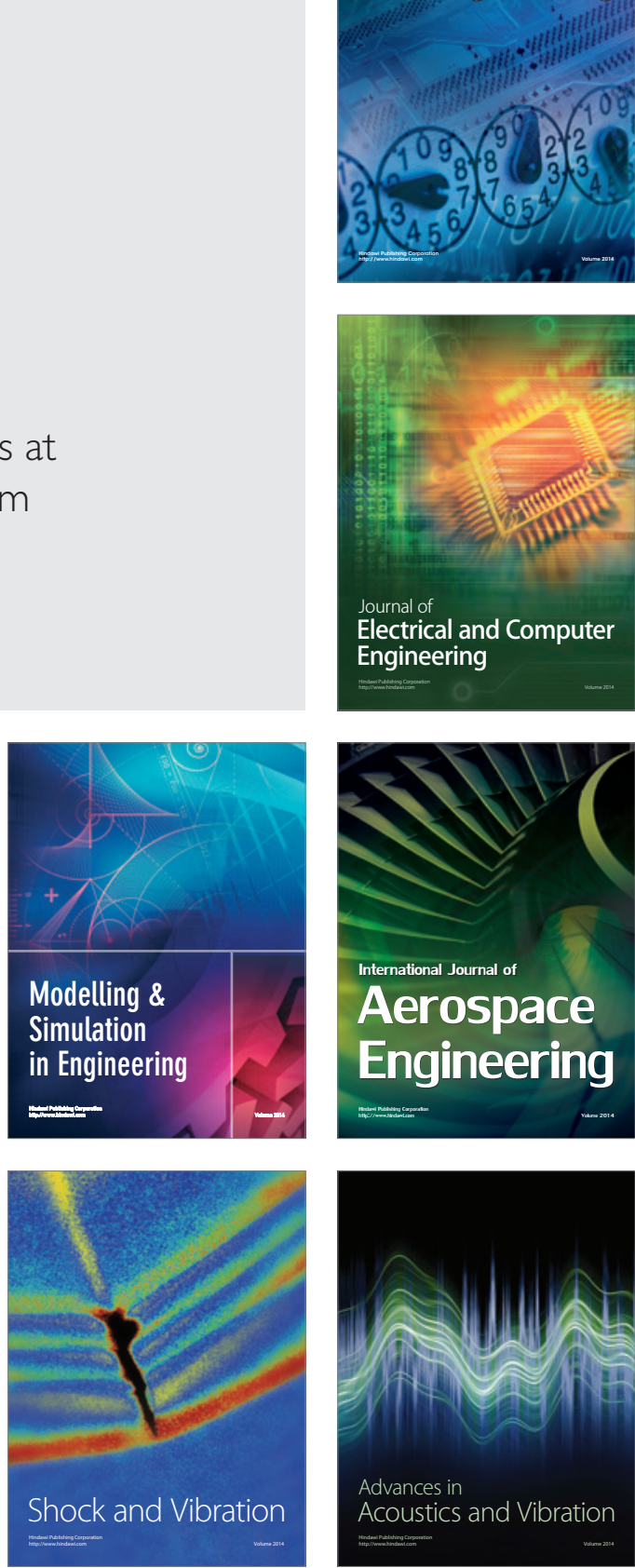